\title{
Baseline Obesity Increases 25-Year Risk of Mortality due to Cerebrovascular Disease: Role of Race
}

\author{
Shervin Assari ${ }^{1, *}$ and Mohsen Bazargan ${ }^{1,2}$ \\ 1 Department of Family Medicine, Charles R. Drew University of Medicine and Science, Los Angeles, \\ CA 90059, USA; Mohsenbazargan@cdrewu.edu \\ 2 Department of Family Medicine, University of California, Los Angeles (UCLA), Los Angeles, CA 90095, USA \\ * Correspondence: assari@umich.edu
}

Received: 2 September 2019; Accepted: 28 September 2019; Published: 1 October 2019

\begin{abstract}
Background: Although obesity may have a role as a risk factor for cerebrovascular mortality, less is known about how demographic and social groups differ in this regard. Aims: This study had two aims: first to investigate the predictive role of baseline obesity on long-term risk of mortality due to cerebrovascular disease, and second, to test racial variation in this effect. Methods: the Americans' Changing Lives Study (ACL) 1986-2011 is a state of the art 25-year longitudinal cohort study. ACL followed a nationally representative sample of Blacks $(n=1156)$ and Whites $(n=2205)$ for up to 25 years. Baseline obesity was the main predictor of interest, time to cerebrovascular death was the main outcome of interest. Demographic characteristics, socioeconomic status (educational attainment and household income), health behaviors (exercise and smoking), and health (hypertension and depressive symptoms) at baseline were covariates. Cox proportional hazards models were used to test additive and multiplicative effects of obesity and race on the outcome. Results: From the total 3,361 individuals, 177 people died due to cerebrovascular causes (Whites and Blacks). In the pooled sample, baseline obesity did not predict cerebrovascular mortality (hazard ratio $(\mathrm{HR})=0.86,0.49-1.51$ ), independent of demographic, socioeconomic, health behaviors, and health factors at baseline. Race also interacted with baseline obesity on outcome ( $\mathrm{HR}=3.17,1.09-9.21)$, suggesting a stronger predictive role of baseline obesity on cerebrovascular deaths for Black people compared to White individuals. According to the models that were run specific to each race, obesity predicted risk of cerebrovascular mortality for Blacks (HR $=2.51,1.43-4.39)$ but not Whites $(\mathrm{HR}=0.69,0.31-1.53)$. Conclusions: Baseline obesity better predicts long-term risk of cerebrovascular death in Black individuals compared to White people. More research should explore factors that explain why racial differences exist in the effects of obesity on cerebrovascular outcome. Findings also have implications for personalized medicine.
\end{abstract}

Keywords: Stroke; body mass index; race; ethnicity; mortality

\section{Introduction}

\subsection{Background}

Cerebrovascular conditions such as stroke are leading contributing factors to both morbidity and also mortality in the United States (U.S.) and globally [1,2]. Stroke is the second most common cause of death in the world [3,4]. Stroke kills 5.5 million people and causes 44 million disability-adjusted life-years (DALYs) lost annually [3-5]. Stroke is associated with considerable societal and health care costs due to short-term (in-hospital care, critical care) and long-term care, as well as indirect costs [6]. Epidemiological studies are needed to gain the knowledge that is required for reducing the burden of cerebrovascular conditions [7-9].

The U.S. is experiencing a decline in the incidence of stroke and other cerebrovascular conditions in Whites but not in Blacks [10]. Compared to White Americans, Black Americans are at higher risk of 
stroke [11] and associated mortality [12]. Stroke occurs at an earlier age among Blacks compared to Whites [11]. The relative excess stroke mortality among Blacks compared with Whites is most marked in the population aged less than 65 years [12]. Among men 45 to 54 years old, stroke death is 3.7 times more common in Blacks compared to Whites [12]. Higher mortality of stroke among Blacks is in part due to higher severity of stroke in Blacks than Whites $[12,13]$. Some of the epidemiological risk factors of the excess stroke mortality of Blacks are low socioeconomic status (e.g., education and income) [14], medical risk factors (e.g., hypertension) [15-17], and behavioral factors such as obesity [18].

Obesity is one of the potential mechanisms behind racial disparity in stroke mortality [12]. Obesity, which increases risk of stroke [19-30], is more common among Blacks than Whites [18]. Every $5 \mathrm{~kg} / \mathrm{m}^{2}$ additional body mass index (BMI) is associated with $18 \%$ additional risk of stroke after adjustment for demographic and socioeconomic confounders [19].

With a higher prevalence among Blacks, obesity may be one of the factors explaining racial disparities in cerebrovascular mortality in the U.S. [19]. However, it is still unknown whether obesity differentially increases risk of cerebrovascular mortality in Blacks and Whites. Given the growing literature on Black-White differences in the effects of socioeconomic [10,12], psychological [19,31-36] and medical [37] risk factors on health outcomes, Blacks and Whites may also differ in the salience of obesity on future risk of cerebrovascular mortality. Social class and race are shown to alter the effects of obesity, hostility, and depression on mortality due to diabetes (DM), cardiovascular disease, and renal disease [31,36-38]. One reason behind the differential effect of baseline risk factors on long-term health outcomes is differential stability of risk factors over time [39]. For instance, Black smokers have a higher chance of quitting, due to lower severity of smoking, compared to Whites [39]. As a result, risk factors have differential effects on health outcomes across demographic and social groups [33]. In addition, obesity has different correlates in Whites and Blacks [40-43]. Finally, Blacks and Whites with obesity also have different levels of intention for weight loss [44,45].

\subsection{Aim}

To extend the existing knowledge on how risk factors operate across racial and ethnic groups, this study compared Blacks and Whites for the effect of baseline obesity on risk of cerebrovascular mortality over a 25-year period.

\section{Methods}

\subsection{Design and Setting}

The Americans' Changing Lives (ACL) study is a 25-year longitudinal study in the U.S. The ACL was conducted from 1986 to 2011. More information about design, methods, and sampling of the ACL has been published previously [46-48].

\subsection{Study Population}

ACL used a stratified multistage probability sampling to recruit adults 25 years old or above. All participants were living in the continental U.S. in 1986. The ACL included 3617 non-institutionalized people. The ACL study oversampled older adults (those age 60 and older) and Blacks. The ACL successfully recruited $68-70 \%$ of sampled individuals and households, respectively. Participants entered the ACL and the current analysis regardless of their risk factor profile including but not limited to obesity, substance use, smoking, and alcohol use.

\subsection{Ethics}

The ACL study protocol was approved by the University of Michigan institutional review board (\# AG018418). Informed consent was received from all ACL participants. 


\subsection{Measures}

Data were collected on race, demographic characteristics, socioeconomic factors, and chronic medical conditions (CMC) at the baseline face-to-face interview in 1986. Mortality due to cerebrovascular causes was collected from 1986 to 2011. Baseline obesity was the predictor of interest, and cerebrovascular mortality was the main outcome.

\subsubsection{Exposure}

Obesity, defined as a BMI larger than $30 \mathrm{~kg} / \mathrm{m}^{2}$, was the independent variable. In this study, BMI was measured based on self-reported height and weight. BMI based on self-reported data correlates strongly with measured BMI [49-52].

\subsubsection{Outcome}

Mortality due to cerebrovascular diseases was the main outcome in this study. Information on mortality during the 25 years of follow up was obtained via death certificates, National Death Index (NDI), and the informants (spouse, partner, etc). In most cases, death certificates were enough to verify the time and cause of death. In a handful of cases where death certificates were not enough to verify death, other sources were reviewed for additional information. Occurrence of death was certain in all of the deceased cases. In a handful of cases, however, the date of death was determined by asking an informant or from the NDI report, but not the death certificates [53,54].

In this study, to classify various causes of death, we applied the ICD 9 and 10 codes $[55,56]$. Cause of death was considered as missing if the death certificate and NDI report could not be achieved. ICD 10 as well as ICD 10 systems were used to determine cause of mortality, depending on whether the time of death had been recorded.

\subsubsection{Confounders}

Baseline demographic characteristics, socioeconomic factors, health behaviors, and health status were covariates in this study.

Demographic Factors. Demographic indicators included age and gender (men as the reference group).

Socioeconomic Status (SES) Characteristics. In this study, SES indicators included educational attainment and household income. Educational attainment was a dichotomous variable: 0-11 years of schooling $=0$, and $12+$ years of schooling $=1$. Annual household income was also measured.

Exercise (Physical Activity). To measure physical activity, ACL used a physical activity index, which evaluated how often respondents were engaged in the following three types of activities: (1) taking walks, (2) participating in exercise or active sports, and (3) working in the garden or yard. A four level Likert scale item response was used ranging from "often" to "never." The physical activity score was calculated as the mean of the three items [57]. Higher scores indicated a higher level of physical activity [58].

Smoking (i.e., tobacco use). To measure smoking status, respondents were asked whether they smoke at the time of survey. A dummy variable was defined where non-smokers were the referent category [58].

Depressive Symptomatology. Symptoms of depression were evaluated using the Center for Epidemiological Studies-Depression scale (CES-D) 11-item version [59]. This scale evaluates how much the respondents had felt happy, depressed, lonely, sad, and had restless sleep and somatic symptoms. Abbreviated CES-D measures are both reliable and valid and have similar factor structure compared to the original CES-D scale [60-62]. Item response categories were 1 ("hardly ever") to 3 ("most of the time"). All of the positive items were recoded. Mean CES-D scores were then calculated using all eight items. Thus, baseline depressive symptoms ranged from 1 to 3 . Higher CES-D scores were indicative of a greater severity of depressive symptomatology. 
Hypertension (HTN): Hypertension and six other chronic medical conditions were measured at baseline using a self-reported measure [46,63-65]. Participants were asked whether a health care provider had ever told them that they had a certain chronic disease [53,64].

\subsubsection{Moderator}

Race. Race was the focal moderator in this study. In this study, race was operationalized as a dichotomous variable, either non-Hispanic Whites or non-Hispanic Blacks [reference category]. Race and ethnicity were self-reported and measured at baseline in the year 1986 using several survey items. Hispanics were omitted from this analysis.

\subsection{Statistical Analysis}

Our univariate, bivariate, and multivariable data analyses were performed in Stata 13.0 (Stata Corporation, College Station, TX, USA). Due to the complex survey design (due to the multistage sampling that involved clustering and stratification) of the ACL, Taylor series linearization was used to estimate the standard errors using the sampling weights (due to stratification, clustering, and non-response). All proportions have applied weights. Mean and frequency tables were used to describe our sample. Chi square and independent sample $t$ tests were used for bivariate analyses. A sub-population Cox regression analysis was applied, as our sample was limited to Whites and Blacks.

For the purpose of multivariable analysis, we applied Cox proportional hazards modeling to test if the association between obesity and cerebrovascular mortality is independent of confounders. A list of potential confounders of the association between obesity and cerebrovascular mortality were selected as a priori based on an extensive literature review that showed demographics, socioeconomic factors, health behaviors, and health status should be controlled. In all models, age, gender, education, income, exercise, smoking, hypertension, self-rated health, and depressive symptoms were controlled.

Cox proportional hazards models require an event (death due to cerebrovascular disease) and the time to event (time to death due to cerebrovascular disease). A cerebrovascular cause of death was considered 0 for the respondents who did not die or died due to any other cause of death. Time to the cerebrovascular death event or censoring was calculated as the number of months that had passed from baseline to death, loss to follow up, or the end of the longitudinal cohort study (year 2011).

Model 1 was performed in the pooled sample and included the main effects.

$\log h(t)=f\left[h \_0(t)\right.$, alpha + beta $_{1}$ race + beta $_{2}$ age + beta $_{3}$ gender + beta $_{4}$ education + beta $_{5}$ income

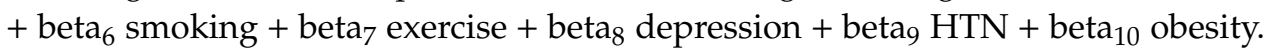

Model 2 was run in the pooled sample and included the race by obesity interaction as well.

$\log h(t)=f\left[h \_0(t)\right.$, alpha + beta $_{1}$ race + beta $_{2}$ age + beta $_{3}$ gender + beta $_{4}$ education + beta $_{5}$

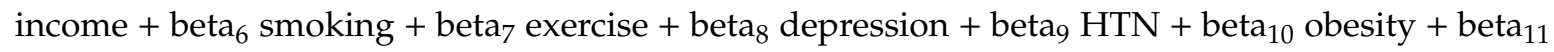
obesity * race.

Model 3 and Model 4 were performed in White and Black people, respectively.

$\log h(t)=f\left[h \_0(t)\right.$, alpha + beta $_{1}$ age + beta $_{2}$ gender + beta $_{3}$ education + beta $_{4}$ income + beta $_{5}$ smoking + beta $_{6}$ exercise + beta 7 depression + beta $_{8}$ HTN + beta9 obesity.

We also ran similar models with overweight $($ BMI $>25)$ instead of obesity $($ BMI $>30)$ as the exposure.

From all these models, hazard ratios (HR) [the values of $\log \left(\right.$ beta $\left.\left._{n}\right)\right]$ and their associated $95 \%$ confidence intervals (CI) were reported from all of the above models. A $p$ value less than 0.05 was regarded as statistically significant. The threshold of the $p$ value was not adjusted as only four regression models were performed. Missing data were less than $5 \%$. 


\section{Results}

\subsection{Descriptive Statistics}

This study followed 3361 individuals for up to 25 years, from which 1156 were Blacks and 2205 were Whites. Table 1 summarizes the descriptive statistics for the pooled sample, and then separately for Whites and Blacks. Blacks were younger, had higher number of chronic medical conditions at baseline in comparison to Whites. Relative to White people, Black individuals had also lower educational attainment $(p<0.05$ for all). Blacks also reported worse self-rated health (SRH) than Whites (Table 1).

Table 1. Descriptive statistics in the pooled sample and also based on race $(n=3361)$.

\begin{tabular}{|c|c|c|c|c|c|c|}
\hline \multirow[t]{2}{*}{ Characteristics } & & \multirow{2}{*}{$\begin{array}{c}\begin{array}{c}\text { Pooled Sample } \\
(n=3361)\end{array} \\
95 \% \text { CI }\end{array}$} & \multicolumn{3}{|c|}{$\begin{array}{c}\text { White } \\
\text { Individuals } \\
(n=2205)\end{array}$} & \multirow{2}{*}{ 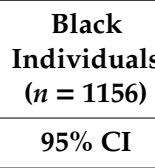 } \\
\hline & $\mathbf{M}$ & & $\mathbf{M}$ & $95 \% \mathrm{CI}$ & $\mathbf{M}$ & \\
\hline \multicolumn{7}{|l|}{ Demographics } \\
\hline Age (Years) & $\begin{array}{c}47.79 \\
\%\end{array}$ & $\begin{array}{c}46.72-48.86 \\
95 \% \text { CI }\end{array}$ & $\begin{array}{c}47.98 \\
\%\end{array}$ & $\begin{array}{c}46.77-49.19 \\
95 \% \text { CI }\end{array}$ & $\begin{array}{c}46.37 \\
\%\end{array}$ & $\begin{array}{c}44.93-47.81 \\
95 \% \text { CI }\end{array}$ \\
\hline \multicolumn{7}{|l|}{ Gender } \\
\hline Men & 47.26 & $44.86-49.68$ & 47.82 & $45.12-50.52$ & 43.18 & $38.79-47.69$ \\
\hline Women & 52.74 & $50.32-55.14$ & 52.18 & $49.48-54.88$ & 56.82 & $52.31-61.21$ \\
\hline \multicolumn{7}{|l|}{ Socioeconomics } \\
\hline \multicolumn{7}{|l|}{ Education * } \\
\hline 11 Years or Less & 23.93 & 21.37-26.70 & 21.71 & $18.87-24.85$ & 40.25 & $34.55-46.24$ \\
\hline \multirow[t]{2}{*}{$>12$ Years } & 76.07 & $73.30-78.63$ & 78.29 & $75.15-81.13$ & 59.75 & $53.76-65.45$ \\
\hline & $\mathrm{M}$ & $95 \%$ CI & $\mathrm{M}$ & $95 \%$ CI & $\mathrm{M}$ & $95 \%$ CI \\
\hline Education * & 12.53 & $12.34-12.73$ & 12.69 & $12.48-12.90$ & 11.37 & $10.90-11.84$ \\
\hline Income $(\$ 1000) *$ & 5.41 & $5.22-5.60$ & 5.57 & $5.36-5.77$ & 4.25 & $3.88-4.62$ \\
\hline \multicolumn{7}{|l|}{ Health } \\
\hline Self-Rated Health * & 2.30 & $2.25-2.35$ & 2.28 & $2.23-2.33$ & 2.43 & $2.32-2.54$ \\
\hline \multirow[t]{2}{*}{$\begin{array}{l}\text { Chronic Medical } \\
\text { Conditions* }\end{array}$} & 0.80 & $0.74-0.85$ & 0.78 & $0.71-0.84$ & 0.92 & $0.82-1.02$ \\
\hline & $\%$ & $95 \% \mathrm{CI}$ & $\%$ & $95 \% \mathrm{CI}$ & $\%$ & $95 \% \mathrm{CI}$ \\
\hline \multicolumn{7}{|l|}{ Health } \\
\hline \multicolumn{7}{|l|}{ Self-Rated Health * } \\
\hline Good or Excellent & 85.06 & $83.33-86.64$ & 85.97 & $84.15-87.60$ & 78.38 & $74.68-81.68$ \\
\hline Poor or Fair & 14.94 & $13.36-16.67$ & 14.03 & $12.40-15.85$ & 21.62 & $18.32-25.32$ \\
\hline Smoking * & 30.45 & $27.81-33.23$ & 29.70 & $26.85-32.72$ & 35.98 & $30.81-41.49$ \\
\hline \multicolumn{7}{|l|}{ Obesity * } \\
\hline No & 85.54 & $83.76-8714$ & 86.48 & $84.47-88.27$ & 78.56 & $74.50-82.13$ \\
\hline Yes & 14.46 & $12.86-1624$ & 13.52 & $11.73-15.53$ & 21.44 & $17.87-25.50$ \\
\hline
\end{tabular}

The overall prevalence of DM was 5.73\%, $(95 \% \mathrm{CI}=4.80-6.82)$. DM was more common in Blacks $(9.22 \%, 95 \% \mathrm{CI}=7.75-10.95)$ than Whites $(5.25 \%, 95 \% \mathrm{CI}=4.24-6.50)$. This difference was significant at a p of 0.05 . Similarly, overall, people had 12.53 years of schooling at baseline ( $95 \% \mathrm{CI}=12.34-12.73$ ). A comparison of racial groups showed higher educational attainment in Whites $(12.69,95 \% \mathrm{CI}=$ 12.48-12.90) than Blacks $(11.37,95 \% \mathrm{CI}=10.90-11.84)$. Thus, on average, Whites had more than 1.3 years higher years of schooling than Blacks, which was statistically significant at a p of 0.05 .

\subsection{Cerebrovascular Deaths}

Of the 177 that died, 121 were White (68.36\%) and 56 were Black (31.64\%). Of the 177 that died, 33 were obese $(18.64 \%)$ and 144 were not obese $(81.36 \%)$ at baseline. 
In bivariate association, race was not associated with death due to cerebrovascular (unadjusted HR for Blacks compared to Whites $=0.78,95 \% \mathrm{CI}=0.55-1.11$ ), suggesting that Whites and Blacks had similar risk of future cerebrovascular mortality over 25 years.

In bivariate association, baseline obesity was not associated with future risk of cerebrovascular mortality (Unadjusted HR for Blacks compared to Whites $=0.84,95 \% \mathrm{CI}=0.45-1.56$ ), suggesting that Whites and Blacks had a similar risk of future cerebrovascular mortality over 25 years.

\subsection{Bivariate Correlations}

Table 2 presents bivariate correlation between the study independent variables, moderator, confounders, and the outcome. Race (Black) was negatively associated with education and income but positively associated with depressive symptoms, hypertension, and obesity. Blacks more frequently smoked and less frequently exercised. Race was not associated with cerebrovascular death. Baseline obesity was associated with female gender and less education, income, smoking, and exercise. Obesity at baseline was associated with depressive symptoms and hypertension at baseline. Obesity at baseline was not associated with cerebrovascular death in the pooled sample (Table 2).

Table 2. Correlation matrix of the study variables $(n=3361)$.

\begin{tabular}{|c|c|c|c|c|c|c|c|c|c|c|c|}
\hline Characteristics & 1 & 2 & 3 & 4 & 5 & 6 & 7 & 8 & 9 & 10 & 11 \\
\hline 1 Race & $1.00 *$ & & & & & & & & & & \\
\hline 2 Age & $-0.06 *$ & 1.00 & & & & & & & & & \\
\hline 3 Gender & $0.05 *$ & 0.11 * & 1.00 & & & & & & & & \\
\hline 5 Income & $-0.29 *$ & $-0.30 *$ & $-0.20 *$ & $0.52 *$ & 1.00 & & & & & & \\
\hline 6 Smoking & $0.06^{*}$ & $-0.21 *$ & $-0.07 *$ & 0.00 & -0.02 & 1.00 & & & & & \\
\hline 7 Exercise & $-0.16^{*}$ & $-0.24 *$ & $-0.16^{*}$ & $0.28 *$ & 0.27 * & $-0.05 *$ & 1.00 & & & & \\
\hline 8 Depressive Symptoms & $0.17 *$ & $-0.07 *$ & $0.11 *$ & $-0.19 *$ & $-0.24 *$ & $0.09 *$ & $-0.21 *$ & 1.00 & & & \\
\hline 11 Death to cerebrovascular disease & -0.01 & $0.21 *$ & $0.04 *$ & $-0.07 *$ & $-0.09 *$ & $-0.06^{*}$ & $-0.07 *$ & 0.02 & $0.07^{*}$ & 0.01 & 1.00 \\
\hline
\end{tabular}

\subsection{Models in the Pooled Sample}

Table 3 summarized the results of Model 1 and Model 2. According to Model 1 in the pooled sample, baseline obesity did not predict cerebrovascular mortality $(\mathrm{HR}=0.86,0.49-1.51)$, independent of demographic, socioeconomic, health behaviors, and health factors at baseline. According to Model 2 , race interacted with baseline obesity on outcome ( $\mathrm{HR}=3.17,1.09-9.21)$, suggesting a stronger association between baseline obesity and future risk for cerebrovascular deaths for Blacks, in comparison to Whites (Table 3).

\subsection{Models in Whites and Blacks}

Table 4 summarized the results of Model 3 and Model 4 in Whites and Blacks, respectively. As Model 3 shows, obesity did not predict the outcome in Whites (HR $=0.69,0.31-1.53)$. Model 4 shows that obesity predicts risk of cerebrovascular mortality for Blacks (HR $=2.51,1.43-4.39)$ (Table 4). 
Table 3. Pooled sample Cox proportional hazards models with time of death due to cerebrovascular disease as the outcome $(n=3361)$.

\begin{tabular}{|c|c|c|c|c|}
\hline \multirow{2}{*}{ Characteristics } & HR (SE) & $95 \%$ & HR (SE) & $95 \%$ \\
\hline & \multicolumn{2}{|c|}{$\begin{array}{c}\text { Model } 1 \\
\text { Main Effect Model }\end{array}$} & \multicolumn{2}{|c|}{$\begin{array}{c}\text { Model 2 } \\
\text { Model with Interaction }\end{array}$} \\
\hline \multicolumn{5}{|l|}{ Demographics } \\
\hline Age (Years) & $1.14(0.01) * * *$ & $1.12-1.17$ & $1.14(0.01)^{* * *}$ & $1.12-1.17$ \\
\hline Gender (Women) & $0.57(0.13) *$ & $0.36-0.91$ & $0.57(0.13) *$ & $0.36-0.90$ \\
\hline Race (Blacks) & $0.78(0.17)$ & $0.50-1.22$ & $0.57(0.16) *$ & $0.33-1.00$ \\
\hline \multicolumn{5}{|l|}{ Socioeconomics } \\
\hline Education (Low) & $0.99(0.04)$ & $0.91-1.07$ & $0.98(0.04)$ & $0.91-1.07$ \\
\hline Income (Low) & $0.92(0.05)$ & $0.82-1.04$ & $0.92(0.05)$ & $0.82-1.04$ \\
\hline \multicolumn{5}{|l|}{ Health Behaviors } \\
\hline Smoking & $1.53(0.41)$ & $0.89-2.62$ & $1.51(0.40)$ & $0.88-2.59$ \\
\hline Exercise & $1.02(0.10)$ & $0.84-1.23$ & $1.01(0.10)$ & $0.84-1.23$ \\
\hline \multicolumn{5}{|l|}{ Health } \\
\hline Depressive Symptoms (>M+SD) & $1.22(0.10) *$ & $1.04-1.44$ & $1.23(0.10) *$ & $1.04-1.45$ \\
\hline Hypertension & $1.41(0.30)$ & $0.91-2.17$ & $1.41(0.31)$ & $0.91-2.19$ \\
\hline \multicolumn{5}{|l|}{ Obesity } \\
\hline Obese & $0.86(0.24)$ & $0.49-1.51$ & $0.69(0.27)$ & $0.31-1.53$ \\
\hline Obese $\times$ Race $($ Blacks) & - & - & $3.17(1.68)^{*}$ & $1.09-9.21$ \\
\hline
\end{tabular}

Table 4. Stratified Cox proportional hazards models with time to death due to cerebrovascular disease as the outcome.

\begin{tabular}{|c|c|c|c|c|}
\hline \multirow[t]{2}{*}{ Characteristics } & \multirow{2}{*}{$\begin{array}{c}\begin{array}{c}\text { Model } 3 \\
\text { Whites } \\
(n=2205)\end{array} \\
\text { HR (SE) }\end{array}$} & \multicolumn{3}{|c|}{$\begin{array}{c}\text { Model } 4 \\
\text { Blacks } \\
(n=1156)\end{array}$} \\
\hline & & $95 \% \mathrm{CI}$ & HR (SE) & $95 \% \mathrm{CI}$ \\
\hline \multicolumn{5}{|l|}{ Demographics } \\
\hline Age (Years) & $1.15(0.02) * * *$ & $1.12-1.19$ & $1.10(0.02)^{* * *}$ & $1.07-1.13$ \\
\hline Gender (Women) & $0.59(0.14) *$ & $0.36-0.95$ & $0.35(0.11)^{* *}$ & $0.19-0.67$ \\
\hline \multicolumn{5}{|l|}{ Socioeconomics } \\
\hline Education (Low) & $0.96(0.05)$ & $0.88-1.06$ & $1.09(0.04) *$ & $1.01-1.17$ \\
\hline Income (Low) & $0.94(0.06)$ & $0.82-1.07$ & $0.78(0.06)^{* *}$ & $0.67-0.91$ \\
\hline \multicolumn{5}{|l|}{ Health Behaviors } \\
\hline Smoking & 1.64(0.48) \# & $0.92-2.94$ & $0.73(0.32)$ & $0.30-1.76$ \\
\hline Exercise & $1.06(0.10)$ & $0.87-1.29$ & $0.66(0.13)^{*}$ & $0.44-0.98$ \\
\hline \multicolumn{5}{|l|}{ Health } \\
\hline Depressive Symptoms $(>\mathrm{M}+\mathrm{SD})$ & $1.24(0.11) *$ & $1.03-1.49$ & $1.26(0.20)$ & $0.91-1.74$ \\
\hline Hypertension & $1.52(0.34) \#$ & $0.96-2.40$ & $0.61(0.20)$ & $0.31-1.20$ \\
\hline \multicolumn{5}{|l|}{ Obesity } \\
\hline Obese & $0.69(0.27)$ & $0.31-1.53$ & $2.51(0.70)^{* *}$ & $1.43-4.39$ \\
\hline
\end{tabular}

\section{Discussion}

According to our findings, race interacts with baseline obesity on long-term risk of cerebrovascular mortality. Compared to White individuals, Black people may be more vulnerable to the effect of baseline obesity on cerebrovascular mortality over a 25-year period. Given the representative nature of the ACL sample, the results are generalizable to the U.S. general population. 
This study introduces obesity as a risk factor that disproportionately contributes to the risk of cerebrovascular conditions among Blacks [11-13]. Our finding emphasizes the role of obesity as an established risk factor for stroke and other cerebrovascular conditions [19-30]. This finding suggests that obesity may be one of the explanatory factors behind Black-White disparities in stroke mortality in the U.S.

Our findings are in line with a growing literature on differential effects of risk factors on a wide range of health outcomes [31-37,66-69]. For social risk factors, however, the effects are systematically larger for Whites than Blacks [70]. In our study, however, obesity was a stronger risk factor for Blacks than Whites.

According to a joint statement by the American Stroke Association (ASA) and American Heart Association (AHA), Blacks and other minorities arrive later to an emergency department, wait longer in the emergency department, and have a lower chance of receiving thrombolysis for acute ischemic stroke. Differential treatment, defined as the presence of bias in the delivery of care is also important. Minorities experience longer stays in rehabilitation services and have poorer functional status compared to Whites. Minorities do not receive equal treatment for either primary or secondary prevention of stroke compared with Whites [70].

Disproportionate prevalence of obesity between Whites and Blacks may explain racial disparities in stroke mortality [12]. Obesity, which increases risk of stroke [19-30], is more common among Blacks [18]. Each $5 \mathrm{~kg} / \mathrm{m}^{2}$ higher BMI is associated with $18 \%$ additional risk for stroke after adjustment for sociodemographic confounders. Additional control for the three metabolic risk factors (i.e., blood pressure, cholesterol, and glucose) reduces the additional risk of stroke to $4 \%$, suggesting that more than three quarters of the additional risk of BMI for stroke is due to blood pressure, cholesterol, and glucose. From these metabolic risk factors, blood pressure seemed to be the most salient explanatory factor, as it accounted for $65 \%$ of the excess risk for stroke. Both overweight (BMI between 25 and 30 $\mathrm{kg} / \mathrm{m}^{2}$ ) and obesity (BMI equal or larger than $30 \mathrm{~kg} / \mathrm{m}^{2}$ ) are associated with an additional risk of stroke, compared to the individuals with normal weight (BMI between 20 and $25 \mathrm{~kg} / \mathrm{m}^{2}$ ). The study showed that $98 \%$ and $69 \%$ of the excess risk of stroke due to overweight and obesity is mediated by glucose, blood pressure, and cholesterol level [19].

Our findings support the "differential vulnerability" theory [32,67-73], which conceptualizes race, ethnicity, gender, SES, and place as contextual effect modifiers that alter susceptibility to a wide range of psychosocial risk factors on health outcomes including but not limited to mortality. In this view, race, gender, class, place, and social, behavioral, psychological, and medical risk factors have multiplicative rather than additive effects. That is, the effect of each risk factor is specific to the sub-population.

The evidence is still mixed regarding factors that explain the higher burden of metabolic, cardiac, and cardiovascular outcomes. The differential effect of risk factors is not specific to cerebrovascular disease and extends to all-cause mortality $[32,67,71]$, renal disease mortality $[37,72]$ and cardiovascular conditions [36,38]. Thus, as a general rule, one size does not fit all, and groups differ in social, behavioral, psychological, and medical determinants of health and illness.

In the US, race is a proxy of social class and socioeconomic status. As a result, most racial disparities in health are a function of sociological rather than biological factors [74]. Studies have shown that the predictive power of risk factors on mortality depend on class [75] and race [32,34,66,67]. Therefore, our findings on the interaction between race and obesity on mortality may be due to socioeconomic factors or race itself. This differential effect may be due to a higher chronicity of obesity in Blacks [44,45,76,77].

Blacks and Whites may have different body images and may have different tolerances of obesity. This is evident by research showing that obese Blacks have lower depression and are less frequently interested in weight loss. Blacks and Whites may have different levels of error in reporting weight and height. Due to cultural issues, cognitive styles, socioeconomics, health literacy, numeracy skills, and validity of self-reported BMI may differ between Blacks and Whites. However, a lower validity of BMI would not strengthen the predictive role of obesity on mortality for Blacks. Based on more tolerance, 
the author expected a lower predictive role of BMI for Blacks. However, our finding is not in agreement with the general pattern reported before [46,78-80] and the Black-White health paradox [81,82].

Mehta et al. used the cross-sectional NHANES data to examine the interactions between five mortality risk factors, namely race, sex, educational attainment, smoking, and obesity [52]. The study showed that several of these behavioral risk factors, including obesity, have differential effects across demographic and socioeconomic groups [52]. Assari has also summarized the results of more than 40 papers that show differential effects between Whites and Blacks [70]. Williams and Kessler have emphasized the need for systematic investigation of interactions between race and risk factors on health $[83,84]$. Kaufman, however, has discussed the difficulty of such an approach due to a wide range of potential methodological biases, such as residual confounding and the association of race with the distribution of several risk factors [85].

Differential vulnerability is a neglected aspect of health disparities research. Differential vulnerabilities may contribute to higher burden of cerebrovascular disease in Blacks. Most of the previous focus has been on higher exposure to risk factors such as hypertension, obesity, and other factors such as SES, health care use, and differential treatment [11,12]. Thus, there is still a need for more research on the role of the differential vulnerability of Blacks and Whites.

Although obesity was associated with a larger effect on the long-term risk of cerebrovascular mortality for Blacks than Whites, the literature shows that Whites may be more vulnerable to the effects of education on both obesity [86] and hospitalization [87]. In a study, educational attainment better predicted the risk of all-cause mortality for Whites than Blacks [67]. This paradoxical pattern requires additional investigation.

We found a higher prevalence of obesity in Blacks than Whites. The environment is more obesogenic for Blacks than Whites, and we discussed this issue. A larger proportion of Blacks live in urban areas that are characterized by food deserts, fast foods, poor park and green spaces. There are a few citations regarding the diet-induced obesity difference between Blacks and Whites [88]. In addition, southern Black culture is linked to obesogenic food [89].

\subsection{Limitations}

The first and foremost limitation of our study was lack of data on any biological marker, such as cholesterol, glucose, arterial thickening, etc. The study did not collect data on the number or nature of cerebrovascular events, as well as their treatments. It is unclear if Blacks are more likely to have cerebrovascular events or they are more likely to die because of cerebrovascular events due to bias of treatment effect. The study did not collect data on a wide range of medical conditions such as history of stroke. The study also measured hypertension based on self-reported data and may be subjected to recall bias. Data were also old, thus there is a need to replicate these finding using more recent data. In addition, Hispanics were removed from the analysis, as our line of research has compared non-Hispanic White and non-Hispanic Blacks for the effect of risk and protective factors. This needs to be clearly stated and justified. Future research should also validate BMI based on self-reported height and weight across racial groups. Finally, BMI, HTN, and other study variables were subject to change over time, and its change was not modeled in this study. Despite these limitations, our results are an extension of the existing literature on racial health disparities in stroke and other cerebrovascular conditions. Major strengths of this study included a (1) nationally representative sample, (2) large sample size, and (3) long-term follow up.

\subsection{Implications}

Our findings may have some clinical and public health implications for reducing racial disparities in cerebrovascular mortality in the U.S. Our findings suggest that universal intervention for prevention of obesity may have differential effects in reducing cerebrovascular mortality in Whites and Blacks.

These results are important given the increasing epidemics of obesity in the U.S. [60,76]. Stroke, cerebrovascular, and cardiovascular disease is the largest contributor to the Black-White health 
disparities in life expectancy. A higher burden of stroke in Blacks compared to Whites is persistent $[10,90]$. A population-based study in the U.S. showed that the incidence of ischemic stroke declined from 1993 to 2010 in Whites [91], however, the incidence did not decline among Blacks, which was suggestive of widened racial disparities in stroke incidence [91]. Other studies have reported similar findings [10].

\subsection{Future Research}

Our results suggest directions for future research. Future studies should examine whether obese Whites and Blacks die from different causes or not. The role of competing risks such as cardiovascular conditions are still unknown. There is a need for replication of these findings in other large data sets. Finally, it is still unclear which behaviors or factors explain the disproportionate risk of mortality of Whites and Blacks from certain causes including but not limited to cerebrovascular events.

Differential vulnerability may be a neglected contributing factor to the higher burden of cerebrovascular disease among Blacks and other minority groups [70]. A single risk factor may have a weaker or stronger effect on health conditions across racial and ethnic groups. The links between race, ethnicity, social class, risk factors, and health outcomes such as mortality are not additive but multiplicative and non-linear. Race not only changes the exposure but also the vulnerability and susceptibility to the risk and protective factors. A better understanding of heterogeneities in the effects of risk factors needs further research.

\section{Conclusions}

Race may alter the long-term effect of baseline obesity on deaths due to cerebrovascular disease. In the U.S., obesity may be differently salient for cerebrovascular disease mortality for Blacks than Whites.

Author Contributions: Conceptualization, S.A.; Formal analysis, S.A.; Funding acquisition, M.B.; Resources, M.B.; Writing - original draft, S.A.; Writing - review \& editing, S.A. and M.B.

Funding: Research reported in this publication was supported by the National Institute of Minority Health and Health Disparities (NIMHD), of the National Institutes of Health under award number 5S21MD000103. The content is solely the responsibility of the authors and does not necessarily represent the official view of the NIMHD or NIH. Assari and Bazargan are also supported by the NIH under Award 54MD008149, R25 MD007610 (PI: M. Bazargan), 2U54MD007598 (PI: J. Vadgama), and U54 TR001627 (PIs: S. Dubinett and R. Jenders). The ACL is supported by the Grant no AG018418 from the National Institute on Aging (DHHS/NIH).

Conflicts of Interest: The authors declare no conflict of interest.

\section{References}

1. CDC. Prevalence of Stroke-United States, 2006-2010. Weekly 2012, 61, 379-382.

2. Di Carlo, A. Human and economic burden of stroke. Age Ageing 2009, 38, 4-5. [CrossRef]

3. Mukherjee, D.; Patil, C.G. Epidemiology and the Global Burden of Stroke. World Neurosurg. 2011, 76, S85-S90. [CrossRef] [PubMed]

4. Deresse, B.; Shaweno, D. Epidemiology and In-hospital Outcome of Stroke in South Ethiopia. J. Neurol. Sci. 2015, 355, 138-142. [CrossRef]

5. Berkowitz, A.L. Stroke and the Noncommunicable Diseases: A Global Burden in Need of Global Advocacy. Neurology 2015, 84, 2183-2184. [CrossRef]

6. Demaerschalk, B.M.; Hwang, H.M.; Leung, G. US cost burden of ischemic stroke: A systematic literature review. Am. J. Manag. Care 2010, 16, 525-533. [PubMed]

7. Meschia, J.F.; Bushnell, C.; Boden-Albala, B.; Braun, L.T.; Bravata, D.M.; Chaturvedi, S.; Creager, M.A.; Eckel, R.H.; Elkind, M.S.; Fornage, M.; et al. Guidelines for the primary prevention of stroke: A statement for healthcare professionals from the American Heart Association/American Stroke Association. Stroke 2014, 45, 3754-3832. [CrossRef]

8. Goldstein, L.B.; Bushnell, C.D.; Adams, R.J.; Appel, L.J.; Braun, L.T.; Chaturvedi, S.; Creager, M.A.; Culebras, A.; Eckel, R.H.; Hart, R.G.; et al. Guidelines for the primary prevention of stroke: A guideline for healthcare professionals from the American Heart Association/American Stroke Association. Stroke 2011, 42, 517-584. [CrossRef] 
9. Goldstein, L.B.; Adams, R.; Alberts, M.J.; Appel, L.J.; Brass, L.M.; Bushnell, C.D.; Culebras, A.; DeGraba, T.J.; Gorelick, P.B.; Guyton, J.R.; et al. Primary prevention of ischemic stroke: A guideline from the American Heart Association/American Stroke Association Stroke Council: Cosponsored by the Atherosclerotic Peripheral Vascular Disease Interdisciplinary Working Group; Cardiovascular Nursing Council; Clinical Cardiology Council; Nutrition, Physical Activity, and Metabolism Council; and the Quality of Care and Outcomes Research Interdisciplinary Working Group. Circulation 2006, 113, e873-e923.

10. Kleindorfer, D.O.; Khoury, J.; Moomaw, C.J.; Alwell, K.; Woo, D.; Flaherty, M.L.; Khatri, P.; Adeoye, O.; Ferioli, S.; Broderick, J.P.; et al. Stroke incidence is decreasing in whites but not in blacks: A population-based estimate of temporal trends in stroke incidence from the Greater Cincinnati/Northern Kentucky Stroke Study. Stroke 2010, 41, 1326-1331. [CrossRef]

11. Trimble, B.; Morgenstern, L.B. Stroke in Minorities. Neurol. Clin. 2008, 26, 1177-1190. [CrossRef] [PubMed]

12. Howard, V.J. Reasons underlying racial differences in stroke incidence and mortality. Stroke 2013, 44 (Suppl. 1), S126-S128. [CrossRef]

13. Howard, V.J.; Kleindorfer, D.O.; Judd, S.E.; McClure, L.A.; Safford, M.M.; Rhodes, J.D.; Cushman, M.; Moy, C.S.; Soliman, E.Z.; Kissela, B.M.; et al. Disparities in stroke incidence contributing to disparities in stroke mortality. Ann. Neurol. 2011, 69, 619-627. [CrossRef]

14. Karlsen, S.; Nazroo, J.Y. Relation between racial discrimination, social class, and health among ethnic minority groups. Am. J. Public Health 2002, 92, 624-631. [CrossRef] [PubMed]

15. Lindhorst, J.; Alexander, N.; Blignaut, J.; Rayner, B. Differences in hypertension between blacks and whites: An overview. Cardiovasc. J. Afr. 2007, 18, 241-247.

16. Signorello, L.B.; Schlundt, D.G.; Cohen, S.S.; Steinwandel, M.D.; Buchowski, M.S.; McLaughlin, J.K.; Hargreaves, M.K.; Blot, W.J. Comparing diabetes prevalence between African Americans and Whites of similar socioeconomic status. Am. J. Public Health 2007, 97, 2260-2267. [CrossRef] [PubMed]

17. Johnson-Lawrence, V.D.; Griffith, D.M.; Watkins, D.C. The effects of race, ethnicity and mood/anxiety disorders on the chronic physical health conditions of men from a national sample. Am. J. Men's Health 2013, 7, 58S-67S. [CrossRef]

18. Jackson, C.L.; Szklo, M.; Yeh, H.C.; Wang, N.Y.; Dray-Spira, R.; Thorpe, R.; Brancati, F.L. Black-white disparities in overweight and obesity trends by educational attainment in the United States, 1997-2008. J. Obes. 2013, 2013, 140743. [CrossRef]

19. Global Burden of Metabolic Risk Factors for Chronic Diseases Collaboration (BMI Mediated Effects); Lu, Y.; Hajifathalian, K.; Ezzati, M.; Woodward, M.; Rimm, E.B.; Danaei, G. Metabolic mediators of the effects of body-mass index, overweight, and obesity on coronary heart disease and stroke: A pooled analysis of 97 prospective cohorts with 18 million participants. Lancet 2014, 383, 970-983. [CrossRef]

20. Rexrode, K.M.; Hennekens, C.H.; Willett, W.C.; Colditz, G.A.; Stampfer, M.J.; Rich-Edwards, J.W.; Speizer, F.E.; Manson, J.E. A prospective study of body mass index, weight change, and risk of stroke in women. JAMA 1997, 277, 1539-1545. [CrossRef]

21. Kurth, T.; Gaziano, J.M.; Berger, K.; Kase, C.S.; Rexrode, K.M.; Cook, N.R.; Buring, J.E.; Manson, J.E. Body mass index and the risk of stroke in men. Ar. Intern. Med. 2002, 162, 2557-2562. [CrossRef] [PubMed]

22. Hu, G.; Tuomilehto, J.; Silventoinen, K.; Sarti, C.; Männistö, S.; Jousilahti, P. Body mass index, waist circumference, and waist-hip ratio on the risk of total and type-specific stroke. Ar. Intern. Med. 2007, 167, 1420-1427. [CrossRef] [PubMed]

23. Winter, Y.; Rohrmann, S.; Linseisen, J.; Lanczik, O.; Ringleb, P.A.; Hebebrand, J.; Back, T. Contribution of obesity and abdominal fat mass to risk of stroke and transient ischemic attacks. Stroke 2008, 39, 3145-3151. [CrossRef] [PubMed]

24. Yatsuya, H.; Yamagishi, K.; North, K.E.; Brancati, F.L.; Stevens, J.; Folsom, A.R. Associations of obesity measures with subtypes of ischemic stroke in the ARIC Study. J. Epidemiol. 2010, 20, 347-354. [CrossRef]

25. Walker, S.P.; Rimm, E.B.; Ascherio, A.; Kawachi, I.; Stampfer, M.J.; Willett, W.C. Body size and fat distribution as predictors of stroke among US men. Am. J. Epidemiol. 1996, 144, 1143-1150. [CrossRef] [PubMed]

26. Suk, S.H.; Sacco, R.L.; Boden-Albala, B.; Cheun, J.F.; Pittman, J.G.; Elkind, M.S.; Paik, M.C.; Northern Manhattan Stroke Study. Abdominal obesity and risk of ischemic stroke: The Northern Manhattan Stroke Study. Stroke 2003, 34, 1586-1592. [CrossRef] [PubMed]

27. Lu, M.; Ye, W.; Adami, H.O.; Weiderpass, E. Prospective study of body size and risk for stroke amongst women below age 60. J. Intern. Med. 2006, 260, 442-450. [CrossRef] 
28. Kurth, T.; Gaziano, J.M.; Rexrode, K.M.; Kase, C.S.; Cook, N.R.; Manson, J.E.; Buring, J.E. Prospective study of body mass index and risk of stroke in apparently healthy women. Circulation 2005, 111, 1992-1998. [CrossRef]

29. Razinia, T.; Saver, J.L.; Liebeskind, D.S.; Ali, L.K.; Buck, B.; Ovbiagele, B. Body mass index and hospital discharge outcomes after ischemic stroke. Ar. Neurol. 2007, 64, 388-391. [CrossRef]

30. Vemmos, K.; Ntaios, G.; Spengos, K.; Savvari, P.; Vemmou, A.; Pappa, T.; Manios, E.; Georgiopoulos, G.; Alevizaki, M. Association between obesity and mortality after acute first-ever stroke: The obesity-stroke paradox. Stroke 2011, 42, 30-36. [CrossRef]

31. Lewis, T.T.; Guo, H.; Lunos, S.; Mendes de Leon, C.F.; Skarupski, K.A.; Evans, D.A.; Everson-Rose, S.A. Depressive symptoms and cardiovascular mortality in older black and white adults: Evidence for a differential association by race. Circ. Cardiovasc. Qual. Outcomes 2011, 4, 293-299. [CrossRef] [PubMed]

32. Assari, S. Race, sense of control over life, and short-term risk of mortality among older adults in the United States. Arch. Med. Sci. 2017, 13, 1233-1240. [CrossRef] [PubMed]

33. Assari, S. Race and Ethnic Differences in Additive and Multiplicative Effects of Depression and Anxiety on Cardiovascular Risk. Int. J. Prev. Med. 2016, 7, 22. [CrossRef] [PubMed]

34. Moazen-Zadeh, E.; Assari, S. Depressive Symptoms Predict Major Depressive Disorder after 15 Years among Whites but Not Blacks. Front. Public Health 2016, 4, 13. [CrossRef]

35. Assari, S.; Sonnega, A.; Pepin, R.; Leggett, A. Residual Effects of Restless Sleep over Depressive Symptoms on Chronic Medical Conditions: Race by Gender Differences. J. Racial Ethn. Health Disparities 2017, 4, 59-69. [CrossRef]

36. Assari, S. Hostility, anger, and cardiovascular mortality among blacks and Whites. Res. Cardiovasc. Med. 2017, 6, 2. [CrossRef]

37. Moghani Lankarani, M.; Assari, S. Diabetes, Hypertension, Obesity and Long Term Risk of Renal Disease Mortality; Racial and Socioeconomic Differences. J. Diabetes Investig. 2017, 8, 590-599. [CrossRef]

38. Assari, S.; Sonnega, A. Racial Differences in the Predictive Role of High Depressive Symptoms on Incident Heart Disease over 18 Years: Results from the Health and Retirement Study. Res. Cardiovasc. Med. 2016. [CrossRef]

39. Bandiera, F.C.; Assari, S.; Livaudais-Toman, J.; Pérez-Stable, E.J. Latino and Black smokers in the Health and Retirement Study are more likely to quit: The role of light smoking. Tob. Induc. Dis. 2016, 14, 23. [CrossRef]

40. Assari, S. Additive Effects of Anxiety and Depression on Body Mass Index among Blacks: Role of Ethnicity and Gender. Int. Cardiovasc. Res. J. 2014, 8, 44-51.

41. Assari, S.; Caldwell, C.H. Gender and Ethnic Differences in the Association between Obesity and Depression among Black Adolescents. J. Racial Ethn. Health Disparities 2015, 2, 481-493. [CrossRef] [PubMed]

42. Assari, S. Psychosocial Correlates of Body Mass Index in the United States: Intersection of Race, Gender and Age. Iran. J. Psychiatry Behav. Sci. 2016, 10, e3458. [CrossRef] [PubMed]

43. Blostein, F.; Assari, S.; Caldwell, C.H. Gender and Ethnic Differences in the Association Between Body Image Dissatisfaction and Binge Eating Disorder among Blacks. J. Racial Ethn. Health Disparities 2017, 4, 529-538. [CrossRef] [PubMed]

44. Assari, S.; Lankarani, M.M. Mediating Effect of Perceived Overweight on the Association between Actual Obesity and Intention for Weight Control; Role of Race, Ethnicity, and Gender. Int. J. Prev. Med. 2015, 6, 102. [CrossRef] [PubMed]

45. Assari, S.; Lankarani, M.M. The Association Between Obesity and Weight Loss Intention Weaker Among Blacks and Men than Whites and Women. J. Racial Ethn. Health Disparities 2015, 2, 414-420. [CrossRef] [PubMed]

46. Assari, S.; Zivin, K.; Burgard, S. Long-Term Reciprocal Associations Between Depressive Symptoms and Number of Chronic Medical Conditions: Longitudinal Support for Black? White Health Paradox. J. Racial Ethn. Health Disparities 2015, 2, 1-9. [CrossRef]

47. House, J.S.; Lepkowski, J.M.; Kinney, A.M.; Mero, R.P.; Kessler, R.C.; Herzog, A.R. The Social Stratification of Aging and Health. J. Health Soc. Behav. 1994, 35, 213-234. [CrossRef] [PubMed]

48. House, J.S.; Kessler, R.C.; Herzog, A.R. Age, Socioeconomic Status, and Health. Milbank Q. 1990, 68, $383-411$. [CrossRef] 
49. Assari, S. Chronic Medical Conditions and Major Depressive Disorder: Differential Role of Positive Religious Coping among African Americans, Caribbean Blacks and Non-Hispanic Whites. Int. J. Prev. Med. 2014, 5, 405-413.

50. Fonseca Mde, J.; Faerstein, E.; Chor, D.; Lopes, C.S. Validity of self-reported weight and height and the body mass index within the "Pró-saúde" study. Rev. Saude Publica 2004, 38, 392-398.

51. Magnusson, K.; Haugen, I.K.; Østerås, N.; Nordsletten, L.; Natvig, B.; Hagen, K.B. The validity of self-reported body mass index in a population-based osteoarthritis study. BMC Musculoskelet. Disord. 2014, 15, 442. [CrossRef] [PubMed]

52. Mehta, N.; Preston, S. Are major behavioral and sociodemographic risk factors for mortality additive or multiplicative in their effects? Soc. Sci. Med. 2016, 154, 93-99. [CrossRef] [PubMed]

53. Lantz, P.M.; House, J.S.; Lepkowski, J.M.; Williams, D.R.; Mero, R.P.; Chen, J. Socioeconomic factors, health behaviors, and mortality: Results from a nationally representative prospective study of US adults. JAMA 1998, 279, 1703-1708. [CrossRef] [PubMed]

54. Centers for Disease Control and Prevention, National Center for Health Statistics. Instruction Manual, Part 9. ICD-10 Cause-of-Death Lists for Tabulating Mortality Statistics (Updated October 2002 to Include ICD Codes for Terrorism Deaths for Data Year 2001 and WHO Updates to ICD-10 for Data Year 2003). Available online: http://www.cdc.gov/nchs/data/dvs/im9_2002.pdf.pdf (accessed on 1 September 2019).

55. Anderson, R.N.; Miniño, A.M.; Hoyert, D.L.; Rosenberg, H.M. Comparability of cause of death between ICD-9 and ICD-10: Preliminary estimates. Natl. Vital Stat. Rep. 2001, 49, 1-32. [PubMed]

56. Cruz-Flores, S.; Rabinstein, A.; Biller, J.; Elkind, M.S.; Griffith, P.; Gorelick, P.B.; Howard, G.; Leira, E.C.; Morgenstern, L.B.; Ovbiagele, B.; et al. Racial-ethnic disparities in stroke care: The American experience: A statement for healthcare professionals from the American Heart Association/American Stroke Association. Stroke 2011, 42, 2091-2116. [CrossRef] [PubMed]

57. Sherer, M.; Maddux, J.E.; Mecadante, B.; Prentice-Dunn, S.; Jacobs, B.; Rogers, R.W. The self-efficacy scale: Construction and validation. Psychol. Rep. 1982, 51, 663-671. [CrossRef]

58. Harvey, I.S.; Alexander, K. Perceived social support and preventive health behavioral outcomes among older women. J. Cross Cult. Gerontol. 2012, 27, 275-290. [CrossRef] [PubMed]

59. Radloff, L.S. The CES-D scale: A self-report depression scale for research in the general population. Appl. Psychol. Meas. 1977, 1, 385-401. [CrossRef]

60. Amtmann, D.; Kim, J.; Chung, H.; Bamer, A.M.; Askew, R.L.; Wu, S.; Cook, K.F.; Johnson, K.L. Comparing CESD-10, PHQ-9, and PROMIS depression instruments in individuals with multiple sclerosis. Rehabil. Psychol. 2014, 59, 220-229. [CrossRef]

61. Zhang, W.; O’Brien, N.; Forrest, J.I.; Salters, K.A.; Patterson, T.L.; Montaner, J.S.; Hogg, R.S.; Lima, V.D. Validating a shortened depression scale (10 item CES-D) among HIV-positive people in British Columbia, Canada. PLoS ONE 2012, 7, e40793. [CrossRef]

62. Andresen, E.M.; Malmgren, J.A.; Carter, W.B.; Patrick, D.L. Screening for depression in well older adults: Evaluation of a short form of the CES-D (Center for Epidemiologic Studies Depression Scale). Am. J. Prev. Med. 1994, 10, 77-84. [CrossRef]

63. Assari, S. Combined Racial and Gender Differences in the Long-Term Predictive Role of Education on Depressive Symptoms and Chronic Medical Conditions. J. Racial Ethn. Health Disparities. 2017, 4, 385-396. [CrossRef] [PubMed]

64. Lankarani, M.M.; Assari, S. Association between number of comorbid medical conditions and depression among individuals with diabetes; race and ethnic variations. J. Diabetes Metab. Disord. 2015, 14, 56. [CrossRef] [PubMed]

65. Houle, J.N. Depressive symptoms and all-cause mortality in a nationally representative longitudinal study with time-varying covariates. Psychosom. Med. 2013, 75, 297-304. [CrossRef]

66. Assari, S. Perceived Neighborhood Safety Better Predicts Risk of Mortality for Whit.es than Blacks. J. Racial Ethn. Health Disparities 2017, 4, 937-948. [CrossRef]

67. Assari, S.; Lankarani, M.M. Race and Urbanity Alter the Protective Effect of Education but not Income on Mortality. Front. Public Health 2016, 4, 100. [CrossRef] [PubMed]

68. Assari, S. General Self-Efficacy and Mortality in the USA. Racial Differences. J. Racial Ethn. Health Disparities 2017, 4, 746-757. [CrossRef] 
69. Assari, S. Socioeconomic Determinants of Systolic Blood Pressure; Minorities' Diminished Returns. J. Health Econ. Dev. 2019, 1, 1-11.

70. Assari, S. Unequal Gain of Equal Resources across Racial Groups. Int. J. Health Policy Manag. 2018, 7, 1-9. [CrossRef]

71. Assari, S.; Moazen-Zadeh, E.; Lankarani, M.M.; Micol-Foster, V. Race, Depressive Symptoms, and All-Cause Mortality in the United States. Front. Public Health 2016, 4, 40. [CrossRef]

72. Dowd, J.B.; Zajacova, A. Does the predictive power of self-rated health for subsequent mortality risk vary by socioeconomic status in the US? Int. J. Epidemiol. 2007, 36, 1214-1221. [CrossRef] [PubMed]

73. Ferraro, K.F.; Kelley-Moore, J.A. Self-rated health and mortality among black and white adults: Examining the dynamic evaluation thesis. J. Gerontol. B Psychol. Sci. Soc. Sci. 2001, 56, S195-S205. [CrossRef] [PubMed]

74. Assari, S.; Moghani Lankarani, M.; Burgard, S. Black-White Differences in The Effect of Baseline Depressive Symptoms on Deaths Due to Renal Diseases: 25 year Follow up of a Nationally Representative Community Sample. J. Renal Inj. Prev. 2015, 4, 127-134. [PubMed]

75. Williams, D.R.; Sternthal, M. Understanding racial-ethnic disparities in health: Sociological contributions. J. Health Soc. Behav. 2010, 51, S15-S27. [CrossRef] [PubMed]

76. Singh-Manoux, A.; Dugravot, A.; Shipley, M.J.; Ferrie, J.E.; Martikainen, P.; Goldberg, M.; Zins, M. GAZEL Cohort. The association between self-rated health and mortality in different socioeconomic groups in the GAZEL cohort study. Int. J. Epidemiol. 2007, 36, 1222-1228. [CrossRef]

77. Flegal, K.M.; Carroll, M.D.; Kit, B.K.; Ogden, C.L. Prevalence of obesity and trends in the distribution of body mass index among US adults, 1999-2010. JAMA 2012, 307, 491-497. [CrossRef] [PubMed]

78. Krul, A.J.; Daanen, H.A.; Choi, H. Self-reported and measured weight, height and body mass index (BMI) in Italy, the Netherlands and North America. Eur. J. Public Health 2011, 21, 414-419. [CrossRef]

79. Assari, S.; Moghani Lankarani, M.; Burgard, S. Black White Difference in Long Term Predictive Power of Self-Rated Health on All-Cause Mortality in United States. Ann. Epidemiol. 2016, 26, 106-114. [CrossRef]

80. Boyer, G.S.; Templin, D.W.; Goring, W.P.; Cornoni-Huntley, J.C.; Everett, D.F.; Lawrence, R.C.; Heyse, S.P.; Bowler, A. Discrepancies between patient recall and the medical record. Potential impact on diagnosis and clinical assessment of chronic disease. Arch. Intern. Med. 1995, 155, 1868-1872. [CrossRef]

81. Keyes Corey, L.M. The Black-White paradox in health: Flourishing in the face of social inequality and discrimination. J. Personal. 2009, 77, 1677-1706. [CrossRef]

82. Barnes, D.M.; Keyes, K.M.; Bates, L.M. Racial differences in depression in the United States: How do subgroup analyses inform a paradox? Soc. Psychiatry Psychiatr. Epidemiol. 2013, 48, 1941-1949. [CrossRef] [PubMed]

83. Williams, D.R.; Collins, C. U.S. socioeconomic and racial differences in health: Patterns and explanations. Annu. Rev. Sociol. 1995, 21, 349-386. [CrossRef]

84. Kessler, R.C.; Neighbors, H.W. A new perspective on the relationships among race, social class, and psychological distress. J. Health Soc. Behav. 1986, 27, 107-115. [CrossRef] [PubMed]

85. Kaufman, J.S.; Cooper, R.S.; McGee, D.L. Socioeconomic status and health in blacks and whites: The problem of residual confounding and the resiliency of race. Epidemiology 1997, 8, 621-628. [CrossRef] [PubMed]

86. Assari, S.; Thomas, A.; Caldwell, C.H.; Mincy, R.B. Blacks' diminished health return of family structure and socioeconomic status; 15 years of follow-up of a national urban sample of youth. J. Urban Health 2018, 95, 21-35. [CrossRef] [PubMed]

87. Assari, S. Bazargan M.; Minorities' Diminished Returns of Educational Attainment on Hospitalization Risk: National Health Interview Survey (NHIS). Hosp. Pract. Res. 2019. in Press.

88. Bodor, J.N.; Rice, J.C.; Farley, T.A.; Swalm, C.M.; Rose, D. The association between obesity and urban food environments. J. Urban Health 2010, 87, 771-781. [CrossRef] [PubMed]

89. Micklesfield, L.K.; Lambert, E.V.; Hume, D.J.; Chantler, S.; Pienaar, P.R.; Dickie, K.; Puoane, T. Socio-cultural, environmental and behavioural determinants of obesity in black South African women. Cardiovasc. J. Afr. 2013, 24, 369. [CrossRef] 
90. Boehme, A.K.; Siegler, J.E.; Mullen, M.T.; Albright, K.C.; Lyerly, M.J.; Monlezun, D.J.; Jones, E.M.; Tanner, R.; Gonzales, N.R.; Beasley, T.M.; et al. Racial and gender differences in stroke severity, outcomes, and treatment in patients with acute ischemic stroke. J. Stroke Cerebrovasc. Dis. 2014. [CrossRef] [PubMed]

91. White, H.; Boden-Albala, B.; Wang, C.; Elkind, M.S.; Rundek, T.; Wright, C.B.; Sacco, R.L. Ischemic stroke subtype incidence among whites, blacks, and Hispanics: The Northern Manhattan Study. Circulation 2005, 111, 1327-1331. [CrossRef] [PubMed]

C 2019 by the authors. Licensee MDPI, Basel, Switzerland. This article is an open access article distributed under the terms and conditions of the Creative Commons Attribution (CC BY) license (http://creativecommons.org/licenses/by/4.0/). 